\title{
Umbilical Cord Length as an Index of Fetal Activity: Experimental Study and Clinical Implications
}

\author{
ADRIEN C. MOESSINGER, ${ }^{(23)}$ WILLIAM A. BLANC, PALMA A. MARONE AND \\ DIANNE C. POLSEN \\ Divisions of Perinatal Medicine and Developmental Pathology, Departments of Pediatrics and Pathology, Babies \\ Hospital, Columbia-Presbyterian Medical Center, College of Physicians and Surgeons of Columbia University, \\ New York, NY, USA
}

\begin{abstract}
Summary
Umbilical cord length varies considerably and the factors controlling cord length are unknown. Experiments in rat fetuses indicate that (1) restriction of fetal movements by oligohydramnios leads to short cord. The umbilical cords were significantly shorter in proportion to the duration or time of onset of the oligohydramnios. The mean cord length represented $65 \%$ of littermate control values when persistent oligohydramnios was induced on day 15, $71 \%$ for day 16 and $78 \%$ for day 17 (term day 21 ). (2) Suppression of fetal movements by curarization from day 18 on leads to short cords, irrespective of amniotic fluid volume. The paralyzed fetuses with polyhydramnios had a mean cord length representing $85 \%$ of sham operated controls, and those with oligohydramnios and paralysis had a similar mean cord length, $86 \%$ of controls. (3) Extra-uterine pregnancies with the fetuses free in the maternal abdominal cavity, yet attached to their umbilical cords, led to cords measuring $147 \%$ of littermate controls. (4) In contrast, when the extra-uterine fetuses were fixed to the uterine horn, close to the placental implantation site, with little or no stretch applied to the cord, the mean cord length was $90 \%$ of littermate controls.

These results indicate that tensile forces on the cord secondary to fetal movements are important determinants of cord length.
\end{abstract}

\section{Speculation}

The umbilical cord length of the newborn infant might be a reflection of past fetal activity, given adequate space for movement. Cord length could become a useful diagnostic tool since extremes in length may point to unrecognized developmental anomalies.

The length of the umbilical cord varies considerably. The factors controlling cord length have remained obscure and many studies have failed to demonstrate a correlation with several other fetal or maternal characteristics. Leonardo da Vinci observed that the length of the umbilical cord was equal to the height of the infant (10). However, this is only a very rough correlation and the reason why some infants have cords that are either excessively long or dangerously short is unknown (7). The mean length of the umbilical cord is between 50 and $60 \mathrm{~cm}$, with over $85 \%$ of the cords measuring between 40 and $80 \mathrm{~cm}$ (4). In the extremes, cords measuring only a few $\mathrm{cm}$ or as much as $3 \mathrm{~m}$ have been reported (3). Both short and long cords have been associated with an increased risk of intrapartum complications (17).

Recent observations suggest that cord length is a reflection of fetal movement $(13,15,18)$. If this were true, cord length could be an index of fetal motor activity and hence may be a useful diagnostic tool suggesting associated developmental anomalies. This experimental study was conducted to test the hypothesis that longitudinal cord growth occurs in response to direct tensile forces.
In order to determine the validity of a "stretch hypothesis" we have analyzed umbilical cord lengths of the rat fetus in two experimental situations. (1) Decreased tension on the cord was assumed to occur when the fetus was mechanically restrained by the uterus in states of oligohydramnios or by paralysis. In order to determine the respective contributions of fetal akinesia and amniotic fluid loss on cord growth, two groups of fetuses were paralyzed with curare and allowed to develop with either polyhydramnios or oligohydramnios. (2) Increased tension on the cord was assumed to be induced by delivering fetuses in the maternal abdominal cavity, their placentas remaining attached to the uterus. Fetuses tolerate this change in environment well and are found at term to have moved freely to various intra-abdominal sites. To control for the influence of this new environment, a group of fetuses were delivered from the uterus but then fixed to the uterine horn, close to the placental implantation site, thus reducing the possible stretch on the cord. The umbilical cord lengths of experimental fetuses were compared to those of either sham-operated or untouched littermate controls.

\section{MATERIALS AND METHODS}

Sprague-Dawley rats were mated overnight and the presence of sperm in the vaginal smear was taken to indicate day " 0 " of gestation. On specific days (see below) the pregnant rats were subjected to laparotomy under ether anesthesia. Following the surgical procedures, the abdomen was closed and the animals allowed to recover. At term (day 21), the fetuses were delivered abdominally. The umbilical cords were measured to the tenth of a $\mathrm{mm}$ from the placental plate to the abdominal wall using a fine caliper (Mitutoyo Dial Caliper No. 505-646. Mitutoyo Manufacturing Co., Ltd., Tokyo, Japan). The traction applied to the cord when measured was kept constant in all fetuses by pulling horizontally on the placental end until the fetus would slide on the wet bottom of a Petri dish. Initially, the measurements were repeated several times and never varied by more than $0.5 \mathrm{~mm}$. Statistical significance was assessed by the Student $t$ test.

Oligohydramnios. On day 15 of gestation, both uterine horns were exposed. Transuterine puncture of the fetal membranes was performed with a gauge \#22 needle in the fetal sacs on one side, the other horn serving as control. The puncture was considered adequate when withdrawal of the needle was followed by continuous escape of amniotic fluid. Strictly speaking the fluid drained is not only amniotic in origin; due to the persistance of the inverted yolk sac, it contains a small amount of exocoele fluid (1). After verifying that persistent oligohydramnios resulted from the procedure (Fig 1), punctures of the fetal membranes were performed on days $15(n=37), 16(n=31)$ and $17(n=15)$ to determine the influence of varying durations of oligohydramnios on cord length. All fetuses were delivered abdominally at term (17 pregnant animals) and the umbilical cords were measured as outlined above. 
Paralysis. From the 18th day of gestation to term, the experimental fetuses received daily subcutaneous injections of D-Tubocurarine. The dose of curare used was $2 \mathrm{mg} / \mathrm{kg}$ and the volume injected was kept constant at $0.05 \mathrm{ml}$. The concentration for the various days was calculated in advance using a fetal weight chart determined in our laboratory. Five litters were sacrificed $30 \mathrm{~min}$, $4,8,16$ and $24 \mathrm{~h}$ following the injection to determine curare levels (9) in experimental and littermate control fetuses.

Two experimental groups were used. In the first group (I), the fetuses were paralyzed using a transplacental approach with a gauge $\# 30$ needle in order to prevent amniotic fluid leakage. In fact, these fetal sacs contained significantly more fluid (polyhydramnios) after the 19th day and this persisted until term (16). In the second experimental group (II), littermate fetuses were curarized using a gauge \#26.5 needle via the transmembranous route to examine the combined influence of oligohydramnios and fetal paralysis. Sham-operated littermate controls received daily 0.05 $\mathrm{ml}$ injections of saline using the transplacental route, thus preventing leakage (Fig 2). Fourteen pregnant rats were sacrificed at term and the cords were measured in fetuses of group I, group II and sham-operated littermate controls, ( $n=16$ fetuses per group).

Extra-uterine pregnancies. Two experimental groups were used. Group I: on day 18 of gestation, 12 fetuses were delivered from the uterus through a $1 \mathrm{~cm}$ incision and the fetal membranes were

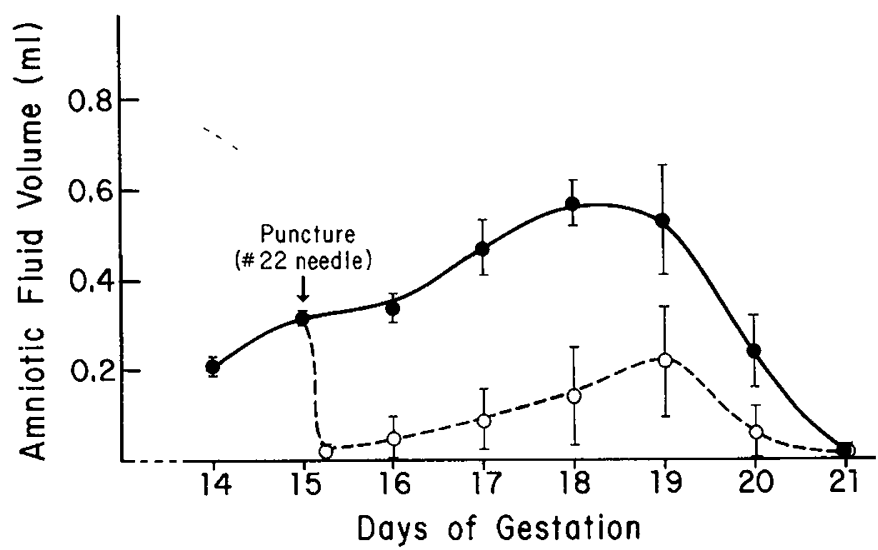

Fig. 1. Amniotic fluid volume following puncture of the fetal membranes. (- - ) control group; (---O---) experimental group.

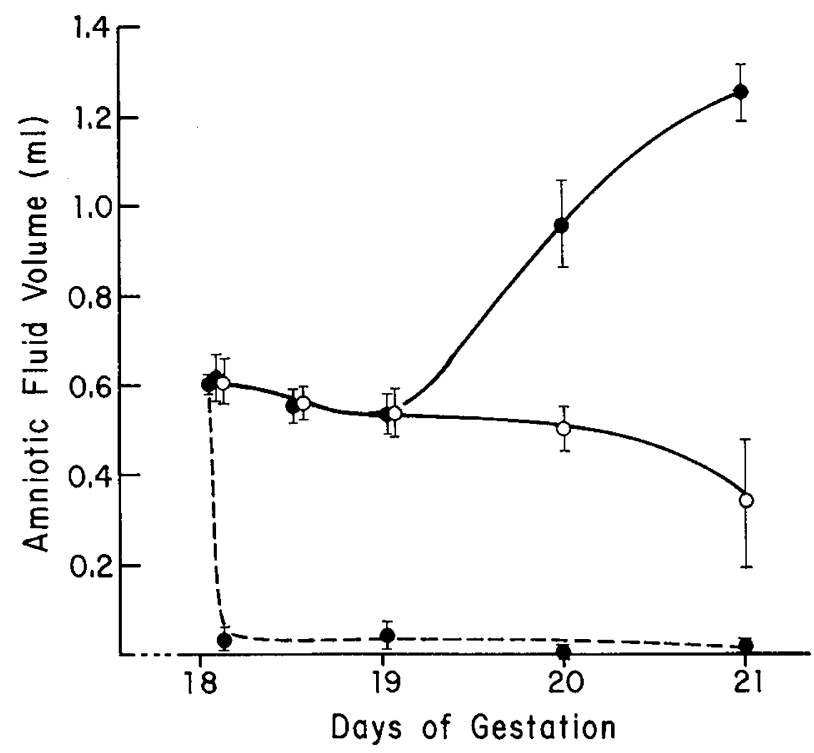

Fig. 2. Amniotic fluid volume following fetal paralysis (rat). (- - ) curare injected with needle passing through the placenta (no leak). (------) curare injected with needle passing through the fetal membranes (leak). (-O-) saline injected using the transplacental approach. removed. The placenta was then secured to the uterus at its implantation site with one marginal silk suture; the uterine horn was partially closed leaving enough space for the passage of the umbilical cord. The fetuses were left free in the maternal abdominal cavity which was then closed. The mothers $(n=7)$ were allowed to recover and the fetuses were delivered abdominally at term.

Group II: on the 18th day of pregnancy, 10 fetuses were delivered from the uterus and their membranes. After partial closure of the uterus, the fetuses were fixed to the uterine horn close to their placental implantation sites by two 6-0 silk sutures. Care was taken not to manipulate the umbilical cord which remained for the most part outside of the uterus, the placenta having been secured in place as above. The fetuses were delivered abdominally at term (six pregnancies). For both experimental groups, untouched littermate controls most similar in body weights were used for comparison.

\section{RESULTS}

Oligohydramnios. The umbilical cord lengths following amniotic sac puncture on days 15,16 and 17 are shown in Table 1 . The umbilical cords were significantly shorter in proportion to the duration or time of onset of the oligohydramnios. The mean cord length represented $65 \%$ of littermate control values when amniocentesis was performed on day $15,71 \%$ for day 16 and $78 \%$ for day 17.

Paralysis. We determined that the experimental fetuses remained paralyzed for at least $16 \mathrm{~h}$ following treatment (with curare levels above $5 \mu \mathrm{g} / \mathrm{ml}$ ) and that littermate controls never reached significant levels (less than $0.2 \mu \mathrm{g} / \mathrm{ml}$ ). These results will be published in detail later.

The umbilical cord lengths following fetal paralysis are shown in Table 2 . The paralyzed fetuses with polyhydramnios had a mean cord length representing $85 \%$ of sham-operated controls, and those with oligohydramnios and paralysis had a similar mean cord length, $86 \%$ of controls.

Extra-uterine pregnancy. The umbilical cord lengths of the fetuses maintained in the maternal abdominal cavity are shown in Table 3. When the fetuses were left free, their cords measured

Table 1. Umbilical cord length following experimental oligohydramnios (rat)

\begin{tabular}{|c|c|c|c|c|}
\hline Duration of & Experimental & Control & & \\
\hline oligohydramnios & mm S.D. & $\mathrm{mm}$ S.D. & $(\%)$ & $P$ \\
\hline Days 15 to 21 & $19.6 \pm 6.7$ & $30.3 \pm 3.9$ & (65) & 0.001 \\
\hline Days 16 to 21 & $21.2 \pm 5.6$ & $29.8 \pm 4.6$ & (71) & 0.001 \\
\hline Days 17 to 21 & $22.7 \pm 4.2$ & $29.2 \pm 4.2$ & (78) & 0.001 \\
\hline
\end{tabular}

Table 2. Umbilical cord length following fetal paralysis (rat) ${ }^{1}$

\begin{tabular}{|c|c|c|c|c|}
\hline $\begin{array}{l}\text { Experimental } \\
\text { groups }\end{array}$ & $\begin{array}{c}\text { Experimental } \\
\mathrm{mm} \text { S.D. }\end{array}$ & $\begin{array}{c}\text { Sham-control } \\
\mathrm{mm} \quad \text { S.D. }\end{array}$ & $(\%)$ & $P$ \\
\hline $\begin{array}{l}\text { Paralysis and } \\
\text { polyhydramnios }\end{array}$ & $25.3 \pm 5.3$ & $29.9 \pm 4.4$ & (85) & 0.013 \\
\hline $\begin{array}{l}\text { Paralysis and } \\
\text { oligohydramnios }\end{array}$ & $25.6 \pm 3.8$ & $29.9 \pm 4.4$ & (86) & 0.005 \\
\hline
\end{tabular}
21).

'The experimental fetuses were paralysed from day 18 to term (day

Table 3. Umbilical cord length in extra-uterine pregnancies $(\text { rat })^{1}$

\begin{tabular}{lccccc}
\hline $\begin{array}{c}\text { Experimental } \\
\text { groups }\end{array}$ & \multicolumn{2}{c}{ Experimental } & \multicolumn{2}{c}{ Control } \\
mm & S.D. & mm S.D. & $(\%)$ & $P$ \\
\hline Fetuses, free & $43.7 \pm 8.1$ & $29.8 \pm 3.5$ & $(147)$ & 0.001 \\
Fetuses, fixed & $27.7 \pm 3.0$ & $30.9 \pm 3.0$ & $(90)$ & 0.025 \\
\hline
\end{tabular}

${ }^{1}$ The experimental fetuses were maintained outside of the uterus from day 18 to term (day 21 ). 
Table 4. Distribution of the length of the human umbilical cord

\begin{tabular}{ccc}
\hline $\begin{array}{c}\text { Length of Cord } \\
(\mathrm{cm})\end{array}$ & No. of Cases & $(\%)$ \\
\hline$<20$ & 39 & $(0.14)$ \\
$20-39$ & 1665 & $(5.97)$ \\
$40-49$ & 5344 & $(19.16)$ \\
$50-59$ & 8387 & $(30.07)$ \\
$60-69$ & 6992 & $(25.07)$ \\
$70-79$ & 3458 & $(12.40)$ \\
$80-89$ & 1358 & $(4.87)$ \\
$\geq 90$ & 646 & $(2.32)$ \\
& & \\
Total & 27889 & $(100)$ \\
\hline
\end{tabular}

${ }^{1}$ Data derived from the Collaborative Perinatal Study (4).

$147 \%$ of littermate controls. In contrast, when they were fixed to the uterine horn, close to the placental implantation site with little or no stretch applied to the cord, the mean cord length at term was $90 \%$ of littermate controls. The cords showed no sign of irritation or stenosis at the level of their passage through the uterine incision.

Body weights. In all three experiments (oligohydramnios, fetal paralysis and extrauterine pregnancy) the body weights of the experimental fetuses were either unaffected or slightly less than controls. The difference (less than $0.5 \mathrm{~g}$ ) was considered too small to significantly affect cord length measurements and was associated with both short and long cords.

\section{DISCUSSION}

The large variation of umbilical cord length in the human is illustrated by Table 4 (Ref. 4). The broad distribution of measurements is quite different from that recorded for any other fetal organ and, even more remarkable, there is no significant correlation between cord length and various other fetal or maternal characteristics such as placental and fetal weight, length of the fetus, parity, maternal age, weight, height, toxemia and blood groups $(11,20)$. This lack of correspondence led Malpas (11) to theorize that the umbilical cord grows in an "autonomic" manner independent of contiguous structures, in contrast to other fetal organs "shaped by a mutual three dimensional restraint between the cells of each organ and its vascular framework".

Our results support the contention that longitudinal cord growth is influenced by tensile forces and depends on both fetal motor activity and space available for movement $(13,15)$. DeMyer and Baird (6) were the first to note short umbilical cords in the rat following amniocentesis but did not provide measurements. We (2) confirmed their observation with quantitative data and now show that the extent of growth inhibition is related to the duration and/or time of onset of oligohydramnios. Following fetal curarization for the last 3 days of gestation, the umbilical cords were significantly shorter, measured $85 \%$ of control values. Of particular interest is the similarity of the effect on cord length whether paralysis was associated with oligo- or polyhydramnios. This suggests that the short cords obtained in the oligohydramnios experiment are not the direct result of amniotic fluid loss per se but are due to partial fetal immobilization by physical restraint. The finding of long cords when the fetuses were left free (yet attached to their umbilical cord) in the maternal peritoneal cavity lends further support to the "stretch hypothesis" for longitudinal cord growth. Diameter and weight of the cord, as well as vascular volume were not determined in this study.

The following clinical observations suggest that stretch regulates human cord growth as well: (1) early obstetric treatises mentioned the frequent association of oligohydramnios with short cords (5). (2) A syndrome of camptodactyly, multiple ankyloses, facial anomalies and pulmonary hypoplasia has been recently delineated in which most patients have both polyhydramnios and short umbilical cords. The syndrome is believed to be related to fetal akinesia $(12,15)$. (3) Miller et al., have documented short umbilical cords in a group of infants for whom there was evidence of early intra-uterine constraint (13) and in one patient with WerdnigHoffmann disease of prenatal onset (14).

The stretch hypothesis could explain why the rate of cord growth decreases after the 28th to 30 th wk of human gestation $(11,20)$, since the fetus occupies progressively more of the intrauterine cavity (from $50-80 \%$ ) in the last trimester, leaving little space for effective trunk movements (14). The observation that twins tend to have slightly shorter cords than singletons (11) could also fit a stretch hypothesis. Long cords have been associated with excessive liquor amnii and coiling of the cord around fetal parts (8). Although the causality of the association is not clear, one could speculate that an active fetus in both situations can exert greater stretch on the cord, thus stimulating its longitudinal growth (14).

We propose that cord length be of concern to the pediatrician since extremes in length could point to unrecognized developmental anomalies. For example, a short cord may indicate decreased fetal activity (e.g., neuromuscular or skeletal disorders) or reduced intra-uterine space (e.g., oligohydramnios, uterine fibroids or malformations with the attendant positional deformation syndromes (19). Conversely, a long cord may indicate increased intrauterine space (e.g., polyhydramnios). Clinical studies are needed to determine if the "stretch hypothesis" can help in predicting abnormal umbilical cord length prenatally or in suggesting associated developmental anomalies at birth. In the meantime, this information may be of value to the dysmorphologist concerned with pathogenetic mechanisms leading to specific developmental anomalies.

\section{REFERENCES AND NOTES}

1. Adolf, E. F.: Ontogeny of volume regulations in embryonic extracellular fluids Q. Rev. Biol., 42: 1 (1967).

2. Ballantyne, G., Moessinger, A. C., James, L. S. and Blanc, W. A.: Short umbilical cord and multiple anomalies in experimental oligohydramnios. Lab. Invest. (Abstract), 3: 382 (1978).

3. Benirschke, K. and Driscoll, S. G.: The pathology of the human placenta. In: Handbuch der Speziellen Pathologischen Anatomie und Histologie VIl/5 pp 159-160. (Springer-Verlag, New York-Berlin-Heidelberg, 1974).

4. Blanc, W. A.: Pathology of the placenta and of perinatal deaths. Chapter 11. In: The Women and Their Pregnancies. Niswander, K. R. and Gordon, M., Ed. (W. B. Saunders, Philadelphia-London-Toronto, 1972).

5. Bret, A. J. and Coupez, F. J.: De la Briéveté du Cordon. Gynécol. et Obstétrique, 55: 3 (1956)

6. De Myer, W. and Baird, I.: Mortality and squeletal malformations from amniocentesis and oligohydramnios in rats: cleft palate, clubfoot, microstromia, and adactyly. Teratology, 2: 33 (1969).

7. Fox, H.: Pathology of the placenta. In: Major Problems in Pathology, James L. Bennington Ed. Vol VII pp 426-427. (W. B. Saunders, London-PhiladelphiaToronto, 1978).

8. Gardiner, J. P.: The umbilical cord. Journal Surgery, Gynecology and Obstetrics, 34: 252 (1922).

9. Horowitz, P. E. and Spector, S.: Determination of serum $d$-tubocurarine concentration by radioimmunoassay. J. Pharmacol. Exp. Ther., 185: 94 (1973).

10. Leonardo da Vinci: Quaderni d'Anatomia. Vangensten. Fohnahn and Hopstock Ed., Vol III: 10, (Dwybwad, Christiania, 1913).

11. Malpas. P.: Length of the human umbilical cord at term. Br. Med. J., I: 673 (1964).

12. Mease, A. D., Yeatman, G. W., Pettett, G., and Merenstein, G. B.: A syndrome of ankylosis, facial anomalies and pulmonary hypoplasia secondary to fetal neuromuscular dysfunction. In: Birth Defects Original Article Series. Bergsma, D., Schinke, R. N., Eds., Vol. XII, 5 p 193, (Alan R. Liss, New York, NY 1976).

13. Miller, M. E., Higginbottom, M. C. and Smith, O. W.: Intrauterine Constraint as a cause of short umbilical cord. Pediatr. Res. (Abstract), 2: 586 (1980).

14. Miller, M. E., Higginbottom, M. C. and Smith, O. W.: Short Umbilical cord: its origin and relevance. Pediatrics, 67: 5 (1981).

15. Moessinger, A. C., Marone, P. A. and Blanc, W. A.: Animal model: syndrome of camptodactyly, multiple ankyloses, facial anomalies, pulmonary hypoplasia polyhydramnios and short umbilical cords. In: The Fetus and the Newborn. Bloom, A. and James, L. S. Eds. (Abstract) Vol XVII p 78 (Alan Liss Inc., New York. NY 1980)

16. Moessinger, A. C., Marone, P. A. and Blanc, W. A.: Etiology of lung hypoplasia: the relative contributions of oligohydramnios and of fetal akinesia. Pediatr. Res., (Abstract) 2: 587 (1980).

17. Rayburn, W. F., Beynen, A. and Brinkman, D. L.: Umbilical cord length and intrapartum complications. Obstet. and Gynecol., 57: 450 (1981). 
18. Singh, S. and Padmanabhan, R.: Growth retardation in rat fetuses induced by chlorpromazine hydrochloride. Anat. Anz., 145: 327 (1979).

19. Smith, D. W.: Recognizable Patterns of Human Deformities. In: Major Problems in Clinical Pediatrics, Vol. XXI. (W. B. Saunders, Philadelphia-London-Toronto, 1981).

20. Walker, C. W. and Pye, B. G.: The length of the human umbilical cord. Br. Med. J., I: 546 (1960)

21. This work was presented at the Annual Meeting of the Society for Pediatric Research, San Francisco, April 1981.

22. The authors thank Dr. R. Matteo for the curare determinations, Drs. G. Ballan- tyne, J. Bassi and F. Mallavo for expert technical assistance. Mrs. Beryl Meikle for typing, and Drs. H. E. Fox, L. S. James and K. F. Schulze for reviewing the manuscript.

23. Requests for reprints should be addressed to: Dr. A. C. Moessinger, Division of Perinatal Medicine, Department of Pediatrics, Babies Hospital, Box 34, 3959 Broadway, New York. NY 10032

24. This research was supported in part by Grants HD-13063 and HL-14218 from the National Institutes of Health and the Florence G. Heller Foundation.

25. Received for publication April 27, 1981

26. Accepted for publication July 15, 1981 .

Copyright $(1982$ International Pediatric Research Foundation, Inc. 